\title{
A PATH UNENVISAGED TO A DESTINATION UNINTENDED: A COLLABORATIVE AUTOETHNOGRAPHIC ACCOUNT OF BECOMING A COMMUNITY OF PRACTICE IN AN HEI
}

\author{
L. Excell* \\ e-mail: Lorayne.excell@wits.ac.za

\section{K. Dixon*} \\ e-mail: Kerryn.dixon@wits.ac.za

\section{Linington* \\ e-mail: vivien.linington@wits.ac.za \\ C. Mathews* \\ e-mail: Corin.mathews@wits.ac.za}

Foundation Studies Division

*University of the Witwatersrand

Johannesburg, South Africa

\section{ABSTRACT}

In this article we explore how a disparate group of predominately foundation phase teacher educators unintentionally, over a period of time, came together to form a strong community of practice (COP). Voluntary involvement in a research project positioned this group of lecturers in unaccustomed roles and necessitated that they engage with each other in a variety of ways to meet project outcomes. Relationships developed as people took on different roles and new responsibilities emerged as the group faced challenges. As this is a subjective interrogation of our experiences, a research method such as autoethnography which focuses on the experience and processes of becoming a CoP, rather than the outcomes of the research itself, is appropriate. We outline our understandings of a CoP and show how, through a critical self-reflective process, we were able to strengthen both our teaching and research practices in a Higher Education Institution (HEI). The strengthening occurred, in part, due to the formation and development of this CoP. Keywords: community of practice, participation, collaborative learning, autoethnography, higher education, foundation phase, self-reflection

\section{INTRODUCTION}

It started as another meeting to plan a poster for a forthcoming conference. This was a final requirement for a three-year European Union (EU) and Department of Higher Education and 
Training (DHET) funded research project to strengthen Foundation Phase (FP) ${ }^{1}$ teacher education. The team was capturing the highlights, constraints, achievements, and lessons learned from the project. It was a lively, insightful discussion. The common thread was that our most powerful learning seemed to have come from interactions with each other. Suddenly it struck us, 'We are becoming a Community of Practice'. It was a moment of realisation. It was also, deeply ironic.

One aspect of our project was to research FP teacher educators' and teachers' views on what constitutes appropriate teaching and learning. This was linked to investigating how supportive and collaborative networks could operate to strengthen practice and lead to the ultimate formation of a FP Community of Practice (CoP) in higher education. We had no intention at the outset of becoming a CoP ourselves, within our university. Our role was to explore if there were current CoPs in this phase and if so where.

The aim of the article is to explore the process of a disparate group of people becoming a CoP and how this has strengthened our own practice as FP teacher educators. There are two reasons for this exploration. The first is the growing realisation in South Africa of the importance of the FP education (DoE 2009) and the recognition that it is an underdeveloped 'field'. The placement of FP teacher education within a university context is also a relatively new phenomenon. Traditionally there has not been a strong culture of research or a strong theorised knowledge base for this phase in the higher education sector (Green, Parker, Deacon and Hall 2011, 110-112). Reasons are many and include the nature of the phase in that it draws on a range of disciplines (e.g. mathematics, literacy, art). These theoretical underpinnings are not always aligned with broader educational and learning theories relevant to this phase. Unlike other school phases where teachers specialise in a particular discipline, FP teachers are required to be generalists grounded in multiple disciplines. This presents particular challenges regarding how much knowledge and expertise is needed in each discipline to develop new skills and expertise related to the Higher Education sector. The consequence is often a conflation of the knowledge needed by teachers compared to the knowledge children need. ${ }^{2}$ The low status of the FP teacher and the perceptions that the job is less demanding and academically rigorous also impacts development of the field.

The second reason for exploring how and why a disparate group of people came together aligns with the CoP literature which usually assumes a developed field of practice. For example, in Lave and Wenger's (1991) early work, the midwives had a well-established knowledge of midwifery. Lave and Wenger (1991) explored how newcomers were inducted into the field and became an integral part of the practice. In this understanding, a CoP is constituted by experts 
as well as novices. In our case this 'mix' was not so because we are working in a developing field as opposed to an established academic context. FP as a rigorous research unit is mostly futuristic as opposed to other phases in education. Thus, when considering the composition of the team, nobody could be considered to be an expert in the field because people came from different disciplines and had different teaching experience. Some had stronger research backgrounds, but no-one had full expertise. Neither was anyone a novice. This composition is unsurprising given the impetus around developing Foundation Phase teacher education in Higher Education.

\section{COMMUNITY OF PRACTICE}

A CoP is a somewhat intuitive and flexible notion lacking precise definition (Iaquinto, Ison and Faggian 2011, 4). It is a social theory which explains learning. Lave and Wenger (1991) argued that people construct and develop their identities and understanding through their active participation and engagement with others in cultural practices that are situated in particular social communities. As Fuller $(2007,19)$ notes 'people learn through their co-participation in the shared practice of the community or the "lived-in-world"'.

According to Lave and Wenger (1991) participation is central to all learning, a notion reinforced by Hagar $(2005,5)$. Participation which includes both process and product allows individuals to become members of the $\mathrm{CoP}$ by 'acquiring the right characteristics (the products of learning)' (Hager 2005, 23). Participants' identities and understandings become increasingly aligned to the practice through advanced participation (Wenger 1998, 4-5).

As Wenger notes $(1998,5)$, social participation as a learning process involves four steps. These are meaning (experiencing our life and world as meaningful); practice (talking about the shared historical and social resources, frameworks, and perspectives that sustain the process); community (recognising the social situations in which our enterprises exist and encouraging competent participation); and finally identity (recognising how learning changes who we are and creates personal histories of 'becoming' within community contexts). These four steps framed the processes we underwent as a team. Perhaps it was the definitive nature of the project (EU/DHET project) and the related activities which enabled our rich social interaction and made it possible for us to identify with the three dimensions of a CoP (Wenger 1998, 73-83), thereby recognising that we were becoming a CoP.

For Wenger (1998, 122-129) the difference between a CoP and another social network is that in a CoP social relations are formed, negotiated and sustained around the activity that has brought the people together. A CoP can be created in different space-time contexts, generating 
different and competing conceptions of the world within and between members. These can be characterised by various degrees of consensus, diversity or conflict among those who identify themselves or are identified by others as belonging to those communities (Wenger 1998, 77; Contu and Willmott 2003, 286).

A CoP is recognisable by the presence of three dimensions which Wenger (1998) has referred to as mutual engagement, joint enterprise and shared repertoire.

\section{Mutual engagement}

Mutual engagement is a collaborative approach in contributing towards goals and the negotiation of meaning to enhance the development of a shared practice. 'Practice does not exist in the abstract. It exists because people are engaged in actions whose meanings they negotiate with one another' (Wenger 1998, 73-74). A CoP thus comprises members whose negotiated relations are organized around what they are there to do. Sharing of practices includes aspects that enable engagement, promote diversity and partiality and encourage mutual relationships.

Enabling elements include safe spaces to exchange ideas and simple comforts like snacks to make work more pleasant (Wenger 1998, 75). Ensuring diversity and partiality means that both differences and similarities are recognised and valued. Disagreement, challenges, and competition are all forms of participation. If these types of issues remain unresolved we argue that the CoP will be weakened. Participants find a unique place and gain a unique identity. This uniqueness is retained as participants are 'woven' together into a mutually beneficial whole.

\section{Joint enterprise}

Through mutual engagement, members of the CoP negotiate their joint enterprise. Participants negotiate responses to their situations creating goals for which they are mutually accountable. These negotiated goals become an integral part of practice. The full complexity of mutual engagement is reflected in the collective negotiation. Total agreement is not the aim of joint enterprise, but rather 'that it is communally negotiated' (Wenger 1998, 78-79).

COPs are not self-contained entities and are positioned within broader systems and often placed within institutions with specific mandates. Huzzard (2004) states that, in the case of academics the institution also has the power to influence relationships between members and to impede or facilitate the participation process. However, even when goals are determined by external forces participants create and own their responses. Responses become the indigenous enterprise of the community and are achieved through a generative process driven by the 
members (Wenger 1998, 79-80), which is then also able to accommodate the unexpected.

\section{Shared repertoire}

A shared repertoire occurs over time. The joint pursuit of an enterprise creates resources for negotiating meaning. The elements of the repertoire can be heterogeneous and include 'routines, words, tools, ways of doing things, stories, gestures, symbols, genres, actions, or concepts that the community has produced or adopted in the course of its existence' (Wenger 1998, 83). A shared repertoire can also include, 'the discourses by which members create meaningful statements about the world' (Wenger 1998, 83).

The repertoire is the community's set of shared resources. Two characteristics enable it to become a resource for the negotiation of meaning. It reflects a history of mutual engagement and it remains inherently ambiguous. Ambiguity does not have a negative connotation in relation to a CoP. 'It is not simply an obstacle to overcome; it is an inherent condition to be put to work’ (Wenger 1998, 84). Ambiguity is a condition of negotiability and enables different interpretations.

\section{CONSTITUTING A CoP}

Much of the CoP literature explores how a CoP operates; the processes and the outcomes and how to sustain and strengthen existing CoPs. According to Fuller $(2007,17-30)$ even Lave and Wenger's (1991) work does not delve deeply into how a CoP is formed. They acknowledge that CoPs have histories and developmental cycles and reproduce themselves in ways that transformation of newcomers becomes remarkably integral to the practice. However, as Fuller and Unwin (2004, 407-426) argue, the concepts of novice and expert are neither stable nor uniform and there is not a one-way transmission of the knowledge from expert to novice. Roles shift depending on the contexts and tasks. Different members bring variety in the richness and extent of their individual learning territories and backgrounds and changing aspirations (Fuller 2007, 17-30). Participation trajectories therefore differ. As we have argued previously no one was a novice, nor were there experts. This 'mix' perhaps explains why we were able to relate our practice to the dimensions of a CoP as identified by Wenger (1998, 73-83).

In later work, which is often quite technicist, this focus on managing and sustaining CoPs continues (Iaquinto, Ison and Faggian 2011, 4-21). Many websites provide the steps one needs to follow. These steps are set up as a process, but, we would argue that there is a difference between a procedure and a process. What they outline is a procedure. (See for example Verago's (2012) outline for creating a COP) The steps do not address the actual processes required in 
setting up the specific dimensions of a CoP such as mutual respect. Other work, particularly in education, examines student learning, or ways to strengthen teacher development (Parker, Patton and Tannehill 2012, 311-327; Jimenez-Silva and Olson 2012, 335-348; Nishino 2012, 1-21). This also does not address the processes of becoming a CoP. Rather it accounts for the procedural. As James (2007, 131-142) asserts little is actually written on how a CoP actually comes into being. This article attempts to address this gap by focusing on the process of becoming a CoP.

\section{COLLABORATIVE AUTOETHNOGRAPHY}

At the beginning of the research project nine racially, culturally, linguistically diverse men and women agreed to be part of the research team. This meant a set of complex social relationships were formed, shaped and reshaped by the project itself. These relationships developed over time as people took on different roles and new responsibilities emerged as the group faced a number of challenges.

As this article is a subjective interrogation of a team's experience, an approach was needed that would enable us to show how the group could be considered to be developing a CoP. The approach had to account for how this happened over time and how people shifted and grew in terms of their knowledge, understanding, and identity constructions. What was crucial is that the multiple voices, perspectives and experiences of the team be foregrounded in exploring the emergence of this CoP. It is for this reason that we chose to use a collaborative autoethnography.

As with Geist-Martin, Gates, Wiering, Kirby, Houston, Lilly and Moreno’s (2010, 1-14) experience in presenting stories of mothering, this methodological approach emerged from a need to explore an experience and interrogate how it informed our own professional practices rather than a predetermined method already designed for the overall research project.

Ngunjiri, Hernandez and Chang (2010) describe autoethnography as 'a qualitative research method that utilizes data about self and its context to gain an understanding of the connectivity between self and others within the same context'. Autoethnography is about process where identification and organization of information through reflexive analysis is required. It is also about the product because the outcome of the analysis is usually presented in an autobiographical account (Enfield and Stasz 2011, 429-447).

As a method of inquiry, autoethnography has become increasingly accepted in academic scholarship (Anderson 2006, 373-395; Ellis and Bochner 2006; Ngunjiri et al. 2010, 3). Autoethnography has been characterized by a greater focus on emotions, an emphasis on selfreflexivity and a postmodern skepticism of knowledge claims. Autoethnographic writing blurs 
and merges a range of genres (Anderson 2006, 373-395). Understandably there have been a number of criticisms leveled against autoethnography. One is that researchers may have a tendency to become self-absorbed and lose sight of others in the contexts in which they live (Anderson 2006) which undermines the principles of ethnographic research. In addition, pressure from the 'community of scientific inquiry' require that methodologies be more systematic and that there is 'methodological transparency' (Ngunjiri et al. 2010).

Collaborative autoethnography has been an attempt to address these concerns. Collaborative autoethnography is a method 'that focuses on self-interrogation but does so collectively and collaboratively within a team of researchers' (Chang et al. in Moore, Scarduzio, Plump and Geist Martin 2013, 6). Ngunjiri et al. (2010) argue that the value of working collaboratively is that researchers can explore their own experiences while gaining a collective understanding of the shared experience. This requires a critical probing that results in insights that go beyond the individual perspective of one researcher.

It is for these reasons that we engaged in a concurrent collaboration model. In this model topics are selected for data collection, autobiographic data is gathered independently, followed by researchers sharing, reviewing and probing stories. After we realized that we were becoming a CoP, some team members wanted to explore this process further. The rest of the team agreed that we could write up these experiences. The experiences represented here are the four authors' and do not speak for all members of the research team although they have provided feedback on the writing of this article. The authors met to discuss our experiences and several topics emerged. From the identified topics we set three questions to frame our autobiographic writing. These were:

- Why did you join the project and why did you remain?

- How do you think that the mentoring programme helped to develop a CoP?

- How do you think conducting research helped to develop a CoP?

We individually generated our autobiographical experiences and via email shared and reviewed input. The autobiographical texts were first coded to establish if the three dimensions of a CoP mutual engagement, joint enterprise and shared repertoire operated. Secondly we identified the processes we underwent in becoming a CoP. Initially we coded texts individually. Then we recoded the texts together. We worked through each text, line by line, to identify categories and emerging patterns. There were several benefits to working this way because we had a dual identity as readers and authors. As readers we could interrogate our own understanding of 
concepts and categories as they emerged in the data, and how the data extended our understanding of the theory. We also had the benefit of probing choices other writers made. This added a rigour in interpreting the nature and 'livedness' of our shared experience as we established a consensus for each line of data.

\section{STORIES OF MUTUAL ENGAGEMENT: WANTING TO LEARN MORE}

We begin with excerpts from our writings that explain the contexts we came from and our motivations for joining the research project.

C, a 'Coloured' man in his forties wrote:

Initially, I had been trained as a senior primary school mathematics teacher. In the past six years I have been drawn closer to working in the FP. I was involved in a research project that looked at the implementation of the curriculum from Grade R to Grade 3. I am currently a project manager in a national research project focused on improving teachers' mathematics teaching in the FP. ... This project ... [allowed me] to close some gaps in my own FP methodology and pedagogy. ... Initially my intentions were academically selfish. Yet my colleagues in the team came with different tensions. Some came with a strong research background and little FP knowledge while others came with strong FP knowledge and little research experience. Surprisingly as I began to engage in the FP discourse I discovered an area of research and development that was both challenging and demanding.

L, a white woman in her early sixties wrote:

... [existing university] departments were being reconstructed. A consequence was that the Early Childhood Development Department ${ }^{3}$ was incorporated into the newly established Foundation Studies division. Having a strong preschool background I viewed this as an unwelcome shift. Shortly thereafter ... [I was informed about the research project]. ... Ironically I who had little FP expertise and who was busy completing a $\mathrm{PhD}$ (so I was a novice in the research field as well) was told to co-ordinate this project and to write the research proposal. I was taken aback but ... [responded accordingly].

$\mathrm{K}$, a white woman in her thirties wrote:

I was not initially part of this project. ... I had been ... asked to head up Foundation Studies. I decided to be a part of the project for two reasons. The first was pragmatic: it made sense to work in a project that already existed and to develop research skills together with staff from the division. The second is that the field of language and literacy education that I worked in did not focus exclusively on the early years. I did not consider myself an expert in the phase. I felt that I needed to learn more - in a way that went beyond practice.

$\mathrm{V}$, a retiree who is FP qualified and remains a project stalwart wrote:

Collegiality born out of similar teaching and research interests prompted me to join the project. I 
came from another division ... but had been involved ... in research and practice linked to Grade R teacher development ... I felt I could contribute, be it in a small way, to a national project ... I could bring a particular expertise ... theories of teaching and learning ... hands-on experience ...

These excerpts tell the story of how we initially came together and tentatively negotiated the way forward. All excerpts reveal that members were driven by an intrinsic motivator, wanting to learn something more. In all cases this was related to the FP. In addition, all members were committed to the broad project brief, strengthening and improving capacity in this phase. These accounts signal the pattern of interaction that characterised mutual engagement in this CoP. As Wenger $(1998,74)$ notes, inclusion in what matters, is one 'requirement for being engaged in a CoP just as engagement is what defines belonging'. This involves active participation and being able to contribute to a goal which for Lave and Wenger (1991) is an essential element of a CoP.

There was a commonality of purpose, to be a part of a national FP project which allowed us to pursue a collective interest. As L noted later in her writing, '... we also shared similar goals, we wanted this project to be a success and recognised each other's individual strengths and limitations ... the collective strength of the team came through its diverse nature'. This characteristic is underscored by Wenger $(1998,76)$ when he contends, 'Homogeneity is neither a requirement for, nor the result of, the development of a community of practice'.

The diverse nature of the group became a strong enabling factor. Not only were we culturally and racially diverse we also came from diverse disciplines. Everybody came with specific strengths and weaknesses. We would argue that we all came with a coherent identity, drawn from previous experience and our specific disciplinary knowledge. We could all contribute something to the project but none could claim to be the FP 'expert'. The fact that we all came with a weakness (in for example, our FP knowledge base, research expertise) is we suggest one of the strengths that enabled us to lay the foundations for developing a strong CoP. We were all vulnerable and recognised and respected this vulnerability in each other. As V wrote:

In an academic world where defence of one's position is often quite vociferous, this willingness to admit 'I got it wrong' was refreshing. It made us vulnerable, open to critique and, [resulted in], both personal and professional growth. ... Team members often said 'I don't know, what do you think?’ The result - sustained co-construction of possible resolution.

\section{C commented:}

... looking back the main reason for remaining [in the project] was that as a group of academics we had created a safe environment for us to be vulnerable. [Admitting] ... that we did not know and that at times we provided the incorrect answers ... [but knowing] we were supported in the 
process. We had discovered that as academics we were both human and fallible and that provided an environment for growth.

Instead of inhibiting participation, this vulnerability enabled us to create a safe space encouraging participation in various ways. The nature of the project and of FP studies allowed members with different disciplinary interests to read themselves into the project in different ways and at different times, affording many opportunities for individuals to engage in the project from a position of strength. People could find a unique place and identity in the project. This perhaps helped to even out the power relations that exist in 'traditional' CoPs constituted by experts and novices because in our CoP, roles shifted depending on context and tasks (Fuller 2007, 17-30).

Having a collective interest and a common goal is a strong factor for initial group cohesion (Wenger 1998) and the desire to 'close some gaps' and to learn new things was essential for this CoP. The group was open to learning through experiences and participation (Hager 2005, 829-846) about the FP, about being researchers, about each other's disciplinary interests, understandings of pedagogy and practice, about mentoring and about each other's lives.

Other enabling elements supported the developing CoP. Different space-time contexts (i.e. road trips, writing retreats,) created opportunities for a range of engagement (Wenger 1998, 79):

When I think about this project a series of mental snapshots springs to mind: us sitting around the table in my office, talking; us sitting around dinner tables ..., talking; us sitting in the kombi as we drove to conferences and meetings, talking; of us laughing even when things were serious and we faced problems we did not know how to solve. Slowly, we have begun to speak, as a group of storytellers telling the same stories in multiple ways. Stories about how we are troubled by the overwhelming needs of a FP system in crisis, by our own university curriculum that falls short of preparing students for the complexities of the classrooms they will enter, of what constitutes knowledge in this phase. But time has shifted our engagements with each other, it has taken away the polite agreement of strangers and replaced it with the outright challenge that only people comfortable with each other have (K).

The more experiences we had together over time in spaces that were often away from our institution meant that a group identity and voice started to emerge. Being together in time and developing safe spaces (Wenger 1998, 75) created a sense of belonging and this manifested in people being willing to take risks and show their vulnerabilities. These space-time experiences were important in building and sustaining dense relationships which are an essential component of a CoP (Wenger 1998, 79).

Humour was an inherent part of all our interactions that helped to develop and sustain the mutual engagement: 
The ability of the team members to laugh at themselves, to laugh with each other but not at each other was a huge 'destressor' as well as something to unite us (L).

We used humour as a sign of affection, as a sign of support, and sometimes black humour as a reminder of our foibles and anxieties, and as a coping mechanism for unexpected challenges. Humour enhanced social interactions, positive or negative, and served to strengthen the groups' mutual engagement.

\section{JOINT ENTERPRISE: SPEAKING WITH THE SAME VOICE}

Wenger $(1998,112)$ notes that CoPs are not self-contained entities but influenced by outside forces. As individuals working at the same university there are norms and expectations for conducting research and for the ways in which we are expected to work that played a role in how the CoP responded to challenges. The mandate set by the DHET which required us to set up a research project as well as to collaborate with another institution, also affected the ways in which this CoP had to negotiate its practices. We have chosen to discuss one aspect of the project, a mentoring programme we designed, that highlights the operation of joint enterprise.

In their accounts, both $\mathrm{C}$ and $\mathrm{K}$ note that the mentoring programme the team established as an aspect of inter-university collaboration was a moment in developing the CoP. K describes the mentoring programme that was put in place as part of the inter-university collaboration to mentor the post graduate students who had registered for a masters degree and the ways in which mentoring was shaped as an indigenous enterprise:

For me the mentoring programme was the starting point that moved us from being a community to becoming a CoP. I think this happened for a number of reasons. The first was that we had no mentoring model in place ... [this was part of the proposal but not] ... how this was to happen. It was only after ... registration ... that we had a sense of what students' needs would be. Mentoring was the first task that we undertook as a group and presented an opportunity for us to work together as a team. ... none of us had had any real mentoring experience. ... Our needs ... did not meet the criteria for conventional mentoring models. How did we mentor students who had little knowledge of the institutional practices of a university or specific knowledge of the phase, and provide academic support for their degree? ... we had to come together and talk about ... [mentoring]. We drew on the expertise we had: people's disciplinary expertise ... interpersonal skills ... This was a new process ... the meetings/debriefings we had as mentors were invaluable.

The meetings took place as the team negotiated goals for working in unchartered territory. Determining how to structure and roll out the mentoring programme provided an opportunity for joint enterprise to become visible. This is seen when $\mathrm{K}$ mentioned that 'we had come together to talk about what our programme needed to look like'. We had found ourselves 
'communally negotiating' (Wenger 1998, 81) the mentoring model and each member accepted responsibility and accountability so that the model worked. Furthermore, C’s account highlights the need for joint negotiation in this mutual collaboration. He flags the unanticipated problems that brought the team together which were solved collectively and informed by institutional practices:

I think the idea of mentoring them, as a group, was the beginning in helping to form this $\mathrm{CoP}$.... It was in the day-to-day engagement that we as the mentors experienced problems. ... [which] called on us to engage with the other mentors and members of the team. ${ }^{4}$ In finding solutions to the problems, we discovered the need to be guided by our professional identity, our expectations as an institution and our reality of a FP work ethic. We began to demonstrate a collective response to problems experienced. ... we identified the problem ..., we discussed [it] ... and collectively implemented the resolution .... We did not always agree. ... [Through] these engagements we discovered how connected we were regarding the fundamentals about FP, teaching and research.

Despite our diversity we developed, as noted by C, a common way of looking at problems, accountability and issues and identifying a collective solution even when we did not always agree, so that, it created a 'situation [that] was liveable' by negotiating our collective goals (Wenger 1998, 79). The issue of mutual accountability re-emerges across the four accounts. These resulted in a negotiated way of being that took into account pragmatic solutions, characterised by a 'shared voice', a common value system and strong group support. K commented on our shared values and ethical responsibilities which were intangible and invisible in the moment when they shaped our decisions. She recalls an incident with a postgraduate students helping on an undergraduate course.

I [had to] manage this incident and I remember the conversation we had about what it meant to work with other people, the responsibilities we needed to take on, and how this shaped our institutional practice. Together we ... handled the incident. I remember really appreciating C's advice on managing people ... feeling totally supported by the team and confident about the solution we had chosen.

And L observed:

When specific student difficulties had to be addressed the coordinator of the mentoring programme knew that she had the collective backing of the team. ... [Through collective transparency] we were able to reinforce academically driven decisions. Students soon came to realise that we were talking with one voice ... working towards similar goals determined by the academic project. This helped to deflect issues from becoming too personalised.

Finally, joint enterprise became embodied in the team through words such as 'we had to come together' (K), 'we had a common way of looking at problems' (C), 'together we worked out 
how to handle the incident' (C), 'we were talking with one voice' (L). Seeking negotiated solutions for challenges presented by the mentoring programme acted as a spur.

\section{SHARED REPERTOIRE: A TAPESTRY OF EXPERIENTIAL LEARNING}

Understandably time has been a crucial component in developing a shared repertoire. In addition, the sustained dense relations that characterised the ways in which mutual engagement manifested over a three-year period in this $\mathrm{CoP}$ also resulted in a shared repertoire. This is evident in the use of shared metaphors people used to make sense of the experience of being together. $\mathrm{C}$ wrote that 'it is the thread that was woven through all of us'. V refers to meaning making as 'a tapestry of experiential learning'. Another supportive factor was the metaphor of story, when we realised that we had begun to speak with 'the same voice' as 'storytellers'.

The development of a shared repertoire is not just characterised by our words but the specific ways of doing things that became routinised (Wenger 1998, 83). On reflection we realised that a pattern emerged in the way we worked and collaborated together. The nature of the collaboration predominantly took place as a group and within the same space(s). We would meet to plan for events like fieldwork. Preparation was usually done in smaller groups. Then there was the event itself which generally opened a space to talk about the work we were doing, or planning to do, and the hilarious polyphonic recounting of events, problems and behaviour of previous trips. Debriefing sessions often combined the procedural with reflection.

Project work such as fieldtrips that enabled moving outside of the institution and working in different time-spaces was crucial for the development of a shared repertoire. It created experiences that resulted in specific ways of doing things, and space to develop a discourse to make meaning of what it meant to be in the FP as a researcher and practitioner in Higher Education. The discourse became characterised by particular kinds of negotiation of meaning. V eloquently recounts her experience that captures these points. We had been doing fieldwork in an inland province as part of our inter-university collaboration and had visited FP classrooms in pairs observing and interviewing teachers.

That evening other team members brought in other problems from their day ... resources unused, teachers unprepared, hygiene compromised .... The reflection that followed went on deep into the night ... caused me to think of one of the unarticulated values of the project - the value of sustained co-thinking and the openness to disagreement. Colleagues who observed the same incidents brought ... their subjective understandings of their perceptions. As a group, we explored our informed knowledge bases to try and understand what had been witnessed. ... Individual 'sacred cows' were interrogated. ... tension was not present. ... [we] shared understandings crafted through negotiation. 
This conversation that went on late into the night has been a touchstone for us and become an integral part of what we shared together. It has shaped the ways we thought about research, working together collaboratively, the challenging context teachers work in, and our pedagogical practice. Most importantly, for this unintentional CoP, this was a decisive moment resulting in a process of 'learning as becoming' (Wenger 1998, 5) where in a variety of ways members of the team have begun to take on stronger researcher identities.

C observed:

... we needed to capture our experiences and lessons learnt. This gave us an opportunity to be involved in writing joint papers in a collaborative style. ... As a team we participated in writing retreats in which we accessed our collective and collaborative research backgrounds.... we had to reflect on our history as a team and the processes of defending our theoretical positions. ... pairs were given certain [writing] tasks ... as a collective we ... [had] to discuss and debate the way in which we would structure the article in collaborative manner.

Writing papers together followed the same patterns that characterised our initial mutual engagement. The negotiation of the joint enterprise of writing is underpinned by mutual responsibility, and the space to be vulnerable and disagree at the same time. This continuity is important. At the same time the demands of writing academic papers strengthens and also subtly alters the repository that is this CoP's growing shared repertoire.

\section{CONCLUSION}

In conclusion it seems germane to ask the question, was this DHET/EU project and the process it generated (collaborative and participatory research to strengthen the FP) a worthwhile endeavour? We would answer unhesitatingly in the affirmative. It has deepened our own insights into this phase of education. We have been afforded opportunities to investigate constraints, to explore challenges and to engage with new possibilities. A CoP is emerging; strengthening us individually and collectively as both teacher educators and researchers. We appear to work far more collaboratively and are much more supportive of each other. In the process we are continuing to strengthen our division and to build academic depth and rigour in this phase.

Sceptics might scoff at these claims but the DHET has recently released information about further DHET/EU research projects; two which specifically involve our division. Deadlines are tight but already there is a collective air of anticipation and preliminary negotiations are underway on how to take this process forward in a participatory manner. As a growing CoP, we recognise in ourselves the four assumptions outlined by Wenger $(1998,4-5)$ which frame a 
CoP, namely the social nature of learning and that knowledge is a matter of competence in a valued enterprises, which in this case is FP. We acknowledge the importance of collaborative participation and agree that collectively we can more effectively engage in new ventures to strengthen our own teaching and research practices as well as those in the broader field of FP teaching and learning at both primary and tertiary levels.

\section{NOTES}

1 In the South African context Foundation Phase includes the first four years of schooling (K-3).

2 As one of our colleagues accounts, her training to be a Foundation Phase teacher was no more than being taught what children needed to learn in grades 1, 2 and 3 at the teacher training college she attended.

3 In our university context ECD refers to the preschool phase. This would be from birth to six, and include the Grade R year. Foundation Phase refers to the formal phase of schooling from Grade R to 3 .

4 Not everyone in the team was a mentor.

\section{REFERENCES}

Anderson, L. 2006. Analytic authoenthnography. Journal of Contemporary Ethnography 35(4): 373395.

Contu, A. and H. Willmott. 2003. Re-embedding situatedness: The importance of power relations in learning theory. Organising Science 14(3): 283-96.

Department of Education. 2009. School realities. Pretoria.

DoE see Department of Education.

Ellis, C. and A. Bochner. 2006. Analysing analytic autoethnography: An autopsy. Journal of Contemporary Ethnography 35(4): 429-449.

Enfield, M. and B. Stasz. 2011. Presence without being present: Reflection and action in a community of practice. Journal of Scholarship of Teaching and Learning 11(1): 108-118.

Fuller, A. 2007. Critiquing theories of learning and community of practice. In Communities of practice. Critical perspectives, ed. J. Hughes, N. Jewson and L. Unwin. New York, Routledge.

Fuller, A. and L. Unwin. 2004. Young people as teachers and learners in the workplace: Challenging the novice-expert dichotomy. International Journal of Training and Development 16(4): 407-26.

Geist-Martin, P., L. Gates, L. Wiering, E. Kirby, R. Houston, A. Lilly and J. Moreno. 2010. Exemplifying collaborative autoethnographic practice via shared stories of mothering. Journal of Research Practice 6(1): Article M8. http://jrp.icaap.org/index.php/jrp/article/ view/2009/187 (accessed 17 June 2014).

Green, W., D. Parker, R. Deacon and G. Hall. 2011. Foundation phase teacher provision by public higher education institutions in South Africa. South African Journal of Childhood Education 1(1): 109119.

Hager, P. 2005. Current theories of workplace learning: A critical assessment. In International handbook of education policy, ed. N. Bascia, A. Cumming, A. Dannow, K. Leithwood and D. Livingstone. Dordrecht, Boston: Kluwer.

Huzzard, T. 2004. Communities of domination? Reconceptualisation organisational learning and power. Journal of Workplace Learning 16(6): 350-361. 
Iaquinto, B., R. Ison and R. Faggian. 2011. Creating communities of practice: Scooping purposeful design. Journal of Knowledge Management 15(1): 4-21.

James, N. 2007. The learning trajectories 'of-old-timers': Academic identities and communities of practice in higher education. In Communities of practice. Critical perspectives, ed. J. Hughes, N. Jewson and L. Unwin. New York, Routledge.

Jimenez-Silva, M. and K. Olson. 2012. A community of practice in teacher education: Insights and perceptions. International Journal of Teaching and Learning in Higher Education 24(3): 335348.

Lave, J. and E. Wenger. 1991. Situated learning. Legitimate peripheral participation. Cambridge: Cambridge University Press.

Moore, J., J. Scarduzio, B. Plump and P. Geist-Martin. 2013. The light and shadow of feminist research mentorship: A collaborative autoethnography of faculty-student research. Journal of research Practice 9(2): Article M8. http://jrp.icaap.org/index.php/jrp/article/ view/343/3009 (accessed 17 June 2014).

Ngunjiri, F., K. Hernandez and H. Chang. 2010. Living autoethnography: Connecting life and research. (Editorial). Journal of Research Pratice 6(1): Article E1. http://jrp.icaap.org/ index.php/jrp/article/view/241/186/ (accessed 17 June 2014).

Nishino, T. 2012. Multi-membership in communities of practice: An EFL teachers' professional development. TESL-EJ 16(2): 1-21.

Parker, M., K. Patton and D. Tannehill. 2012. Mapping the landscape of communities of practice as professional development in Irish physical education. Irish Educational Studies 31(3): 311-327.

Vervago. L. 2012 Creating a community of practice https://www.vervago.com/creating-a-communityof-practice/ (accessed 25 September 2016)

Wenger, E. 1998. Communities of practice: Learning, meaning and identity. Cambridge: Cambridge University Press. 